\title{
MicroRNA-219-5p participates in cyanotic congenital heart disease progression by regulating cardiomyocyte apoptosis
}

\author{
CHUANXIAN HU, SU HUANG, FAFU WU and HUI DING \\ Department of Cardiopulmonary Surgery, Huai'an First People's Hospital, Huai'an, Jiangsu 223300, P.R. China
}

Received March 27, 2019; Accepted September 30, 2020

DOI: $10.3892 /$ etm.2020.9468

\begin{abstract}
MicroRNAs (miRs) play important roles in the protection against and development of congenital heart disease (CHD). However, the role and potential mechanisms of miR-219-5p in cyanotic CHD remains unclear. Reverse transcription-quantitative PCR (RT-qPCR) was used to measure miR-219-5p levels in cyanotic CHD and hypoxia-induced H9C2 cells. Dual luciferase reporter gene assay was used to confirm whether liver receptor homolog-1 (LRH-1) was a direct target of miR-219-5p. miR-219-5p inhibitor and LRH-1-small interfering RNA were transfected into H9C2 cells under hypoxic conditions to investigate the role of miR-219-5p in hypoxia-induced H9C2 cells. Subsequently, cell viability was detected using an MTT assay and cell apoptosis was detected using flow cytometry. In addition, RT-qPCR and western blotting assays were performed to detect the mRNA and protein expression of LRH-1, cyclin D1 and $\beta$-catenin, respectively. The data showed that miR-219-5p expression was higher in patients with cyanotic CHD compared with patients with acyanotic CHD gradually increased in H9C2 cells with prolonged hypoxia time. Dual luciferase reporter assay results showed that LRH-1 was a direct target gene of miR-219-5p. Inhibition of miR-219-5p reversed hypoxia-induced cell viability reduction and attenuated hypoxia-induced cell apoptosis. In addition, hypoxia induction inhibited the expression of LRH-1, cyclin D1 and $\beta$-catenin, which was reversed by miR-219-5p inhibitor. However, LRH-1 downregulation reversed the miR-219-5p inhibitor enhanced cell viability, decreased cell apoptosis and increased expression of LRH-1, cyclin D1 and $\beta$-catenin in hypoxia-treated cardiomyocytes. The present results demonstrated that downregulation of miR-219-5p promoted the expression of the LRH-1/Wnt/ $\beta$-catenin signaling pathway-associated components, reduced cardiomyocyte apoptosis and increased cell growth under hypoxic
\end{abstract}

Correspondence to: Dr Hui Ding, Department of Cardiopulmonary Surgery, Huai'an First People's Hospital, 6 West Beijing Road, Huai'an, Jiangsu 223300, P.R. China

E-mail: dinghui3698@163.com

Key words: congenital heart disease, apoptosis, microRNA-219-5p, liver receptor homolog- $1 / \mathrm{Wnt} / \beta$-catenin signaling pathway conditions. miR-219-5p may be a potential therapeutic target for cyanotic CHD therapy.

\section{Introduction}

Cyanotic congenital heart disease (CHD) is a type of congenital defect that develops during gestation and affects 1/1,000 newborns representing $\sim 10 \%$ of all CHD worldwide $(1,2)$. Progress in surgery and other interventions has improved the treatment of purpuric CHD, however, treatment failure often occurs due to the persistence of cyanosis (3). Chronic hypoxia is the basic pathophysiological process associated with cyanotic CHD (4). Thus, investigation of the protective mechanisms of cardiomyocytes under chronic hypoxia may provide novel treatment strategies for patients with cyanotic CHD.

MicroRNAs (miRNAs/miRs) are a class of highly conserved, non-coding RNA molecules that are 22 nucleotides in length. miRNAs bind to the 3'-untranslated region (UTR) of target mRNAs to regulate gene expression in a post-transcriptional manner (5). Recent studies have proposed that miRNAs play a key role in the progression of CHD $(6,7)$. Existing research has confirmed that miRNA-145 can target frataxin to regulate the development of CHD (6). miR-182 was confirmed to play a protective role in cyanotic CHD by suppressing transcription factor HES1 (7). Studies have reported that miR-219-5p is a tumor suppressor in various cancers, such as glioblastoma and colon cancer $(8,9)$. However, the potential role of miR-219-5p in cyanotic CHD remains unclear.

Liver receptor homolog-1 (LRH-1) is a nuclear receptor which has been implicated in a variety of biological processes, including cell development, lipid homeostasis, embryogenesis and steroidogenesis (10). LRH-1 expression was identified in mouse and human tissues derived from the endoderm, including the liver, intestine and exocrine pancreas, as well as in the ovary and brain $(11,12)$. LRH-1 was reported to play a role in cancer development and progression (13-15). Functional studies have shown that LRH-1 regulated cancer cell growth, apoptosis and invasiveness $(14,15)$. However, the physiological function of LRH-1 in cyanotic CHD remains to be elucidated.

The present study aimed to investigate the role of miR-219-5p in the proliferation and apoptosis of hypoxic cardiomyocytes and its potential mechanisms in the development of cyanotic CHD. 


\section{Materials and methods}

Patients. A total of 30 children diagnosed with CHD in Huai'an First People's Hospital (Huai'an, China) between January 2017 and March 2018, including 15 children with cyanotic CHD (8 females, 7 males; age range, 3.6-16 years) and 15 children with acyanotic CHD ( 8 females, 7 males; age range, 2.9-15 years), were enrolled in the current study. All participants and their legal guardians agreed to the use of their samples in the present study, and written informed consents were obtained from all the legal guardians of all participants. The study protocol was approved by the Ethics Committee of Huai'an First People's Hospital. Standardized anesthesia and operation were performed according to a previous study (16). A biopsy sample was obtained from the right ventricular outflow tract. Myocardium samples were rapidly frozen in liquid nitrogen and stored at $-70^{\circ} \mathrm{C}$ until further use.

Cell culture and treatment. Embryonic rat ventricular myocardial $\mathrm{H} 9 \mathrm{C} 2$ cells were purchased from the American Type Culture Collection and cultured in DMEM (Gibco; Thermo Fisher Scientific, Inc.) supplemented with 10\% FBS (Gibco; Thermo Fisher Scientific, Inc.) and $1 \%$ penicillin/streptomycin. $\mathrm{H} 9 \mathrm{C} 2$ cells were first serum-starved overnight before being incubated in an incubator containing a gaseous mixture of $5 \% \mathrm{CO}_{2}, 94 \% \mathrm{~N}_{2}$ and $1 \% \mathrm{O}_{2}$ (Thermo Fisher Scientific, Inc.) at $37^{\circ} \mathrm{C}$ for $12,24,48$ and $72 \mathrm{~h}$.

Cell transfection. miR-219-5p inhibitor (5'-AGAAUUGCG UUUGGACAAUCA-3') and inhibitor control (5'-CAGUAC UUUUGUGUAGUACAA-3') were synthesized by Shanghai GenePharma Co., Ltd. LRH-1-small interfering RNA (siRNA; cat no. CRR1673) and control-siRNA (cat no. 9500C-20) were obtained from Guangzhou Weijia Technology Co., Ltd (https://whiga.biomart.cn/). A total of $100 \mathrm{nM}$ miR-219-5p inhibitor and $100 \mathrm{nM}$ inhibitor control, $0.2 \mu \mathrm{M}$ LRH-1-siRNA and $0.2 \mu \mathrm{M}$ control-siRNA or $100 \mathrm{nM}$ miR-219-5p inhibitor $+0.2 \mu \mathrm{M}$ LRH-1siRNA were transfected into H9C2 cells using Lipofectamine ${ }^{\circledR} 2000$ (Invitrogen; Thermo Fisher Scientific, Inc.) according to the manufacturer's protocol. Cells were left incubated for $72 \mathrm{~h}$ before transfection efficiency was analyzed with reverse transcription-quantitative PCR (RT-qPCR). Cells without any treatment were used as the control.

Western blot analysis. Total protein from H9C2 cells was extracted using RIPA buffer (Beyotime Institute of Biotechnology) containing protease and phosphatase inhibitors. A bicinchoninic acid protein assay kit (Thermo Fisher Scientific,Inc.) was used to detect protein concentration. Protein lysates ( $40 \mu \mathrm{g}$ per lane) were subjected to $12 \%$ SDS-PAGE and transferred onto PVDF membranes (EMD Millipore). Membranes were blocked for $1 \mathrm{~h}$ at room temperature using $5 \%$ skim milk and subsequently incubated with the following primary antibodies at $4^{\circ} \mathrm{C}$ overnight: LRH-1 (cat no. 12800; 1:1,000; Cell Signaling Technology, Inc.), cyclin D1 (cat no. 2978; 1:1,000; Cell Signaling Technology, Inc.), $\beta$-catenin (cat no. 8480; 1:1,000; Cell Signaling Technology, Inc.) and $\beta$-actin (cat no. 4970; 1:1,000; Cell Signaling Technology, Inc.). The membranes were then incubated with horseradish peroxidase-coupled secondary antibody (anti-rabbit immunoglobulin G, cat no. 7074; 1:1,000; Cell Signaling Technology, Inc.) at room temperature for $2 \mathrm{~h}$. Protein bands were visualized with an ECL western blotting kit (EMD Millipore).

$R T$-qPCR. TRIzol ${ }^{\circledR}$ reagent (Invitrogen; Thermo Fisher Scientific, Inc.) was used to isolate total RNA according to the manufacturer's instructions. cDNA was reverse transcribed from total RNA using a PrimeScript RT Reagent kit (Takara Biotechnology Co., Ltd.) according to the manufacturer's instructions. qPCR was subsequently performed using the SYBR Premix Ex Taq GC kit (Takara Bio, Inc.) on an ABI 7500 thermocycler (Applied Biosystems; Thermo Fisher Scientific, Inc.). The thermocycling conditions were as follows: Initial denaturation $95^{\circ} \mathrm{C}$ for $5 \mathrm{~min}$, followed by 38 cycles of denaturation at $95^{\circ} \mathrm{C}$ for $15 \mathrm{sec}$ and annealing/elongation at $60^{\circ} \mathrm{C}$ for $30 \mathrm{sec}$. The following primer pairs were used for the qPCR: miR-219-5p forward, 5'-ACACTCCAGCTGGGTGAT TGTCCAAACGCAAT-3' and reverse, 5'-CTCAACTGGTGT CGTGGA3'; LRH-1 forward, 5'-GCACGGACTTACACCTAT TGTG-3' and reverse, 5'-TGTCAATTTGGCAGTTCTGG-3'; cyclin D1 forward, 5'-AACTACCTG GACCGCTTCCT-3 and reverse, 5'-CCACTTGAGCTTGTTCACCA-3'; U6 forward, 5'-CTCGCTTCGGCAGCACATAT-3' and reverse, 5'-TTG CGTGTCATCCTTGCG-3' and GAPDH forward, 5'-CTG GGCTACACTGAGCACC-3' and reverse, 5'-AAGTGGTCG TTGAGGGCAATG-3'. GAPDH and U6 were employed as internal controls. Relative expression of genes was calculated using the $2^{-\Delta \Delta C q}$ method (17).

MTT assay. MTT assay was used to measure cell viability. H9C2 cells $\left(4 \times 10^{3}\right.$ cells/well) were seeded into 96-well culture plates. Subsequently, $\mathrm{H} 9 \mathrm{C} 2$ cells were pre-transfected with miR-219-5p inhibitor, inhibitor control or miR-219-5p inhibitor + LRH-1-siRNA for $6 \mathrm{~h}$. The cells were incubated for a further $72 \mathrm{~h}$ in hypoxic and non-hypoxic conditions. Finally, cells were incubated with MTT $(5 \mathrm{mg} / \mathrm{ml})$ for $4 \mathrm{~h}$. A total of $150 \mu \mathrm{l}$ DMSO was added to each well and incubated at $37^{\circ} \mathrm{C}$ for $30 \mathrm{~min}$. A microplate spectrophotometer (Thermo Fisher Scientific, Inc.) was used to measure the absorbance at a wavelength of $450 \mathrm{~nm}$.

Luciferase reporter assay. The potential target genes of miR-219-5p were identified using bioinformatics prediction software MicroRNA.org (http://www.microrna. org/mircrorna/home.do). The results indicated the binding sites between LRH-1 and miR-219-5p, which was further confirmed with a dual luciferase reporter assay. The 3'-UTR of LRH-1 containing the seed sequence of the wild-type (WT) or a mutated (MUT) binding site of miR-219-5p was cloned into psiCHECK-2 vectors (Promega Corporation) to generate psiCHECK-LRH-1-3'UTR-WT and MUT luciferase reporter plasmids. Subsequently, Lipofectamine ${ }^{\circledR} 2000$ (Invitrogen; Thermo Fisher Scientific, Inc.) was used to co-transfect plasmid DNA and miR-219-5p mimic/mimic control into H9C2 cells for $48 \mathrm{~h}$. A dual luciferase reporter assay system (Promega Corporation) was then used to measure the luciferase activity and Renilla luciferase activity was used for normalization.

Flow cytometry assay. Flow cytometry using the Annexin V-FITC apoptosis kit (Beyotime Institute of 

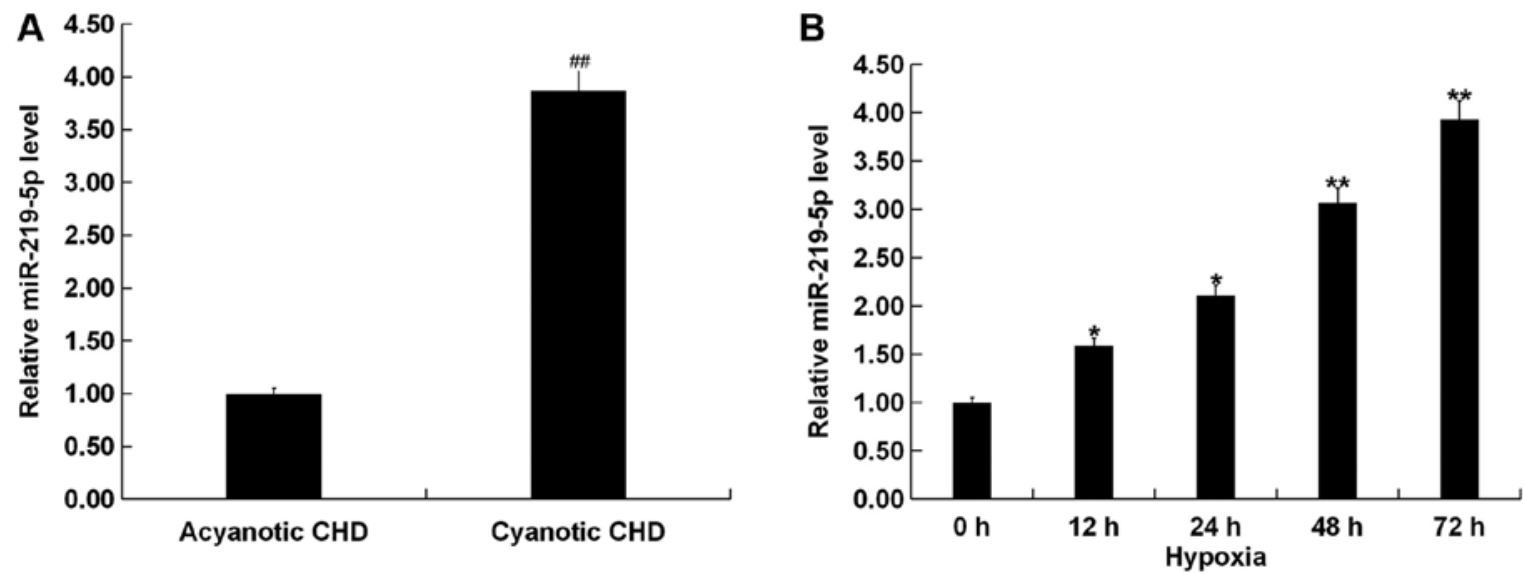

Figure 1. miR-219-5p is upregulated in patients with cyanotic CHD and hypoxic cardiomyocytes. (A) miR-219-5p expression was detected by RT-qPCR analysis in patients with cyanotic CHD and acyanotic CHD. (B) H9C2 cells were exposed to hypoxia for 0, 12, 24, 48 and 72 h. miR-219-5p expression levels were then detected using RT-qPCR. Data are expressed as the mean \pm standard deviation. ${ }^{*} \mathrm{P}<0.05$ and ${ }^{* *} \mathrm{P}<0.01$ vs. 0 h. ${ }^{\# \#} \mathrm{P}<0.01$ vs. acyanotic CHD. CHD, congenital heart disease; RT-qPCR, reverse transcription-quantitative PCR; miR, microRNA.

\section{A 3'-UCUUAACGCAAACCUGUUAGU-5' hsa-miR-219-5p
5'-AUGUUUG | I I I I}

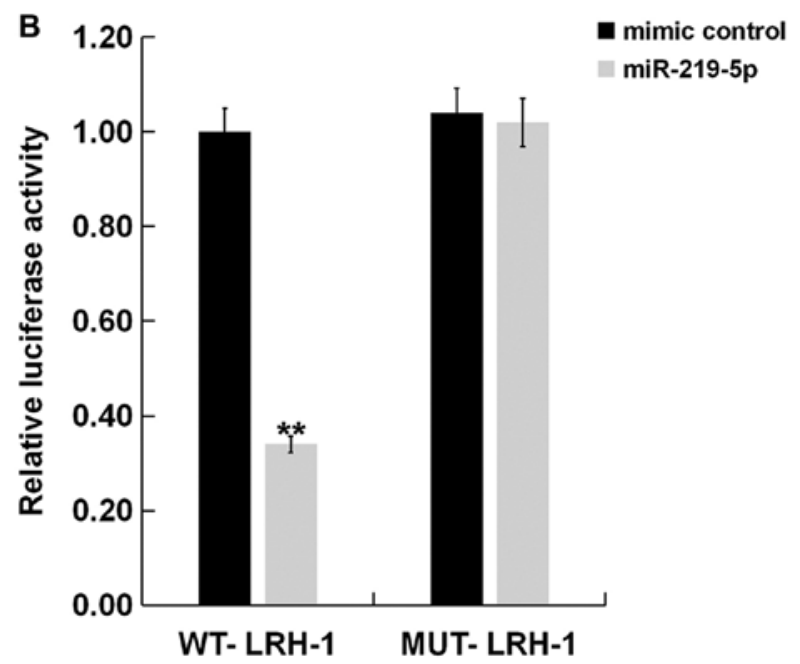

Figure 2. LRH-1 is a target of miR-219-5p. (A) MicroRNA.org showing the predicted binding sites between miR-219-5p and LRH-1. (B) A luciferase reporter assay was performed to reveal the association between miR-219-5p and LRH-1. Data are expressed as the mean \pm standard deviation. ${ }^{* *} \mathrm{P}<0.01$ vs. mimic control. WT-LRH-1, liver receptor homolog-1 wild type; MUT-LRH-1, liver receptor homolog-1 mutant; UTR, untranslated region; miR, microRNA.

Biotechnology) was performed to determine cell apoptosis. H9C2 cells were pre-transfected with miR-219-5p inhibitor, inhibitor control or miR-219-5p inhibitor + LRH-1-siRNA for $6 \mathrm{~h}$. Subsequently, the cells were incubated for a further $72 \mathrm{~h}$ in hypoxic and non-hypoxic conditions. Following treatment, cells were harvested and suspended in $500 \mu \mathrm{l}$ binding buffer. Cells were then double-stained with $5 \mu$ l Annexin V-FITC and $5 \mu 1$ propidium iodide for $10 \mathrm{~min}$ in the dark at room temperature. FACS flow cytometer (BD Biosciences) was used to analyze each sample. Data were analyzed using FlowJo software (version 7.6.1; FlowJo LLC).
Statistical analysis. SPSS 18.0 (SPSS, Inc.) was used to analyze the data. All experiments were performed three times. Results were expressed as the mean \pm SD. Comparisons between groups were determined using Student's t-test or one-way ANOVA with Tukey's post hoc test. $\mathrm{P}<0.05$ was considered to indicate a statistically significant difference.

\section{Results}

miR-219-5p is upregulated in patients with cyanotic CHD and hypoxic cardiomyocytes. RT-qPCR results revealed that the expression of miR-219-5p in patients with cyanotic CHD was significantly higher compared with patients with acyanotic CHD (Fig. 1A). Additionally, H9C2 cells were exposed to hypoxic conditions for 0 (cells under normal oxygen conditions), 12, 24, 48 and $72 \mathrm{~h}$. miR-219-5p was found to gradually increase in a time-dependent manner (Fig. 1B).

$L R H-1$ is a target of miR-219-5p. Bioinformatic results from MicroRNA.org predicted that LRH-1 contained theoretical miR-219-5p binding sites in its 3'-UTR (Fig. 2A). To confirm whether miR-219-5p could directly target the LRH-1 3'-UTR, a luciferase reporter plasmid containing WT and MUT LRH-1 3'-UTR were co-transfected with the miR-219-5p mimic or mimic control into H9C2 cells. As shown in Fig. 2B, co-expression of miR-219-5p mimic significantly inhibited the luciferase reporter activity of the wild-type LRH-1 3'-UTR but not of the mutant LRH-1 3'-UTR. These results suggested that LRH-1 is a direct target of miR-219-5p.

Effects of miR-219-5p inhibitor on cell survival under hypoxic conditions. The potential role of miR-219-5p in hypoxic cardiomyocytes was then investigated. H9C2 cells were transfected with miR-219-5p inhibitor, inhibitor control, LRH-1-siRNA or control-siRNA for $72 \mathrm{~h}$. Transfection efficiencies were detected by RT-qPCR. As shown in Fig. 3A, miR-219-5p expression significantly decreased in miR-219-5p inhibitor-transfected cells compared with the control group. Levels of both mRNA (Fig. 3B) and protein (Fig. 3C) expression of LRH-1 markedly decreased in the 

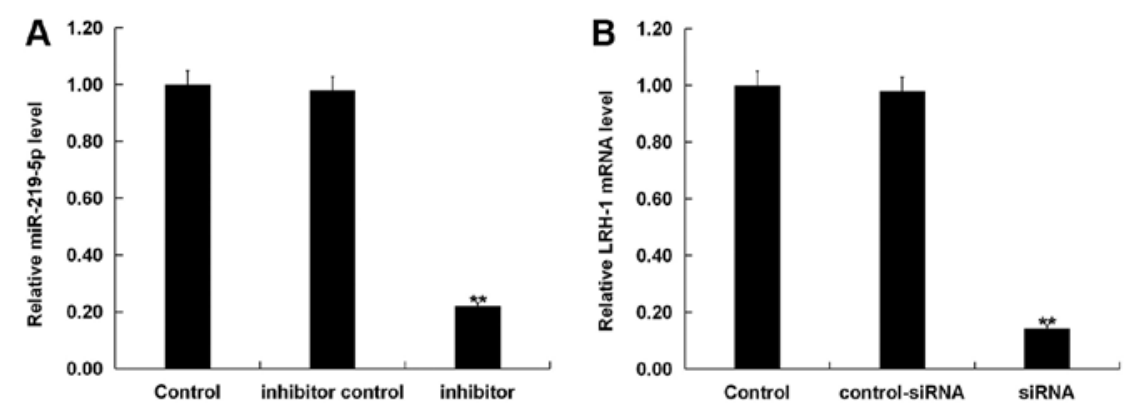

C

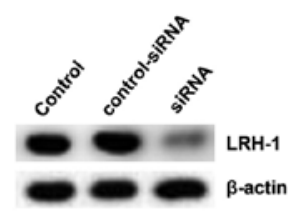

Figure 3. Transfection efficiency of miR-219-5p inhibitor and LRH-1-siRNA. (A) H9C2 cells were transfected with miR-219-5p inhibitor or inhibitor control for $72 \mathrm{~h}$. RT-qPCR was then performed to detect the mRNA levels of miR-219-5p. H9C2 cells were transfected with LRH-1-siRNA or control-siRNA for $72 \mathrm{~h}$. The (B) mRNA and (C) protein expression levels of LRH-1 were detected by RT-qPCR and western blotting, respectively. Data are expressed as the mean \pm standard deviation. ${ }^{* *} \mathrm{P}<0.01$ vs. control. Control, cells without any treatment; inhibitor control, $\mathrm{H} 9 \mathrm{C} 2$ cells transfected with inhibitor control for $72 \mathrm{~h}$; inhibitor, H9C2 cells transfected with miR-219-5p inhibitor for $72 \mathrm{~h}$; siRNA, small interfering RNA; LRH-1, liver receptor homolog-1; miR, microRNA.
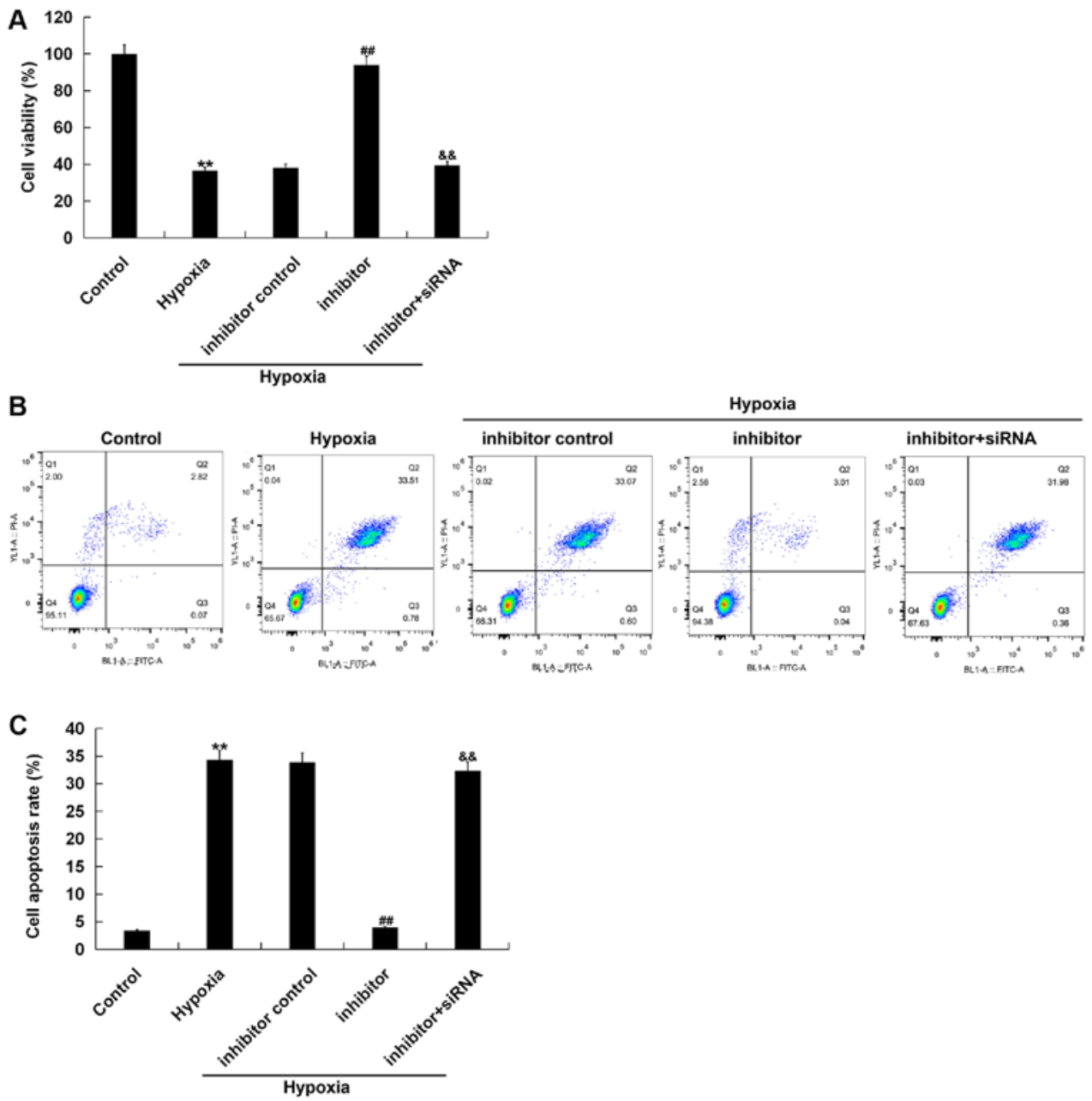

Figure 4. miR-219-5p downregulation increases $\mathrm{H} 9 \mathrm{C} 2$ cell viability and reduces cell apoptosis under hypoxic conditions. H9C2 cells were pre-transfected with miR-219-5p inhibitor, inhibitor control or miR-219-5p inhibitor + LRH-1-siRNA for $6 \mathrm{~h}$ and then the cells were incubated for a further $72 \mathrm{~h}$ in hypoxic and non-hypoxic conditions. (A) Cell viability was measured using an MTT assay. (B) Cell apoptosis was determined using flow cytometry. (C) Quantitative analysis of flow cytometry results. Data are expressed as the mean \pm standard deviation. ${ }^{* *} \mathrm{P}<0.01$ vs. control. ${ }^{\# \#} \mathrm{P}<0.01$ vs. hypoxia. ${ }^{\text {\&\&}} \mathrm{P}<0.01$ vs. inhibitor. siRNA, small interfering RNA targeting liver receptor homolog-1; inhibitor, microRNA-219-5p inhibitor.

LRH-1-siRNA transfection group compared with the control group.

An MTT assay was then performed to detect cell viability. As shown in Fig. 4A, inhibition of miR-219-5p significantly enhanced $\mathrm{H} 9 \mathrm{C} 2$ cell viability in hypoxic conditions at $72 \mathrm{~h}$ compared with cells under hypoxic conditions. Co-transfection of cells with LRH-1-siRNA resulted in significantly reduced cell viability compared with the miR-219-5p inhibitor group.

Downregulation of miR-219-5p inhibits hypoxia-induced cardiomyocyte apoptosis. To investigate whether miR-219-5p played a role in hypoxia-induced apoptosis, flow cytometry 
A

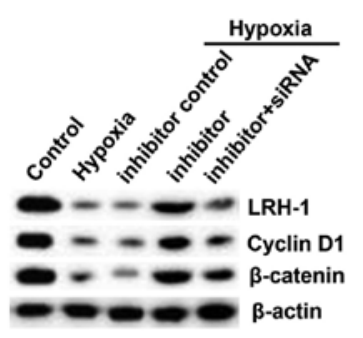

B

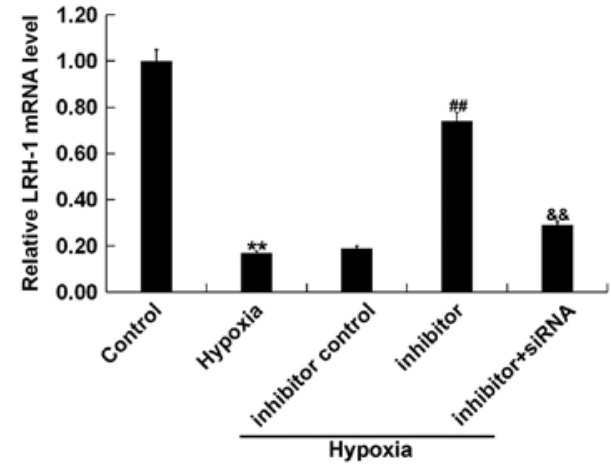

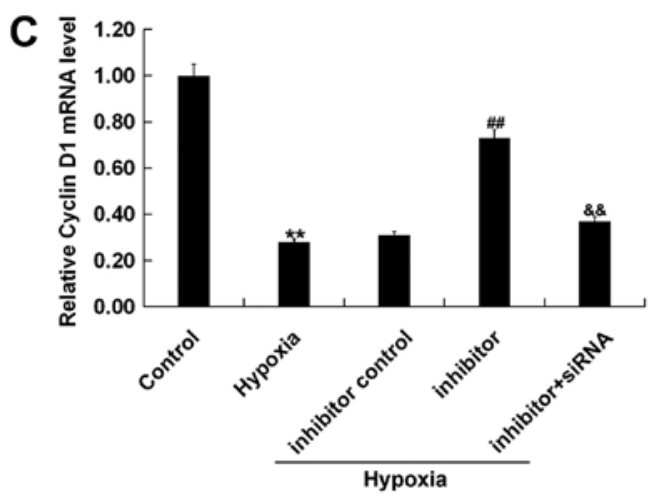

Figure 5. Effects of miR-219-5p downregulation on the LRH-1/Wnt/ $\beta$-catenin pathway in H9C2 cells. The (A) protein and mRNA levels of (B) LRH-1, (C) cyclin D1 and (D) $\beta$-catenin were detected by western blotting and reverse transcription-quantitative PCR, respectively. Data are expressed as the mean \pm standard deviation. ${ }^{* *} \mathrm{P}<0.01$ vs. control. ${ }^{\# \#} \mathrm{P}<0.01$ vs. hypoxia. ${ }^{\&} \mathrm{P}<0.01$ vs. inhibitor. siRNA, small interfering RNA targeting liver receptor homolog-1; inhibitor, microRNA-219-5p inhibitor; LRH-1, liver receptor homolog-1.

was used. Flow cytometry results showed that hypoxia induction significantly enhanced $\mathrm{H} 9 \mathrm{C} 2$ cell apoptosis compared with the control group. Hypoxia-induced apoptosis was significantly reduced by miR-219-5p inhibitor, and this reduction was partially reversed by LRH-1-siRNA transfection (Figs. 4B and C).

Effects of miR-219-5p inhibition on the LRH-1/Wnt/ $\beta$-catenin pathway in hypoxic cardiomyocytes. In order to investigate the possible mechanisms behind the role of miR-219-5p in hypoxic cardiomyocytes, the LRH-1/Wnt/ $\beta$-catenin pathway was studied. H9C2 cells were first transfected with miR-219-5p inhibitor, inhibitor control or miR-219-5p inhibitor + LRH-1-siRNA for $6 \mathrm{~h}$. Subsequently, the cells were incubated for a further $72 \mathrm{~h}$ in hypoxic and non-hypoxic conditions. The mRNA and protein expression levels of LRH-1, cyclin D1 and $\beta$-catenin in $\mathrm{H} 9 \mathrm{C} 2$ cells were then determined. The results indicated that hypoxia induction reduced protein (Fig. 5A) and mRNA (Fig. 5B-D) levels of LRH-1, cyclin D1 and $\beta$-catenin in H9C2 cells. Transfection with miR-219-5p inhibitor increased protein and mRNA levels of LRH-1, cyclin D1 and $\beta$-catenin compared with inhibitor controls. These effects were partially reversed by transfecting cells with LRH-1-siRNA.

\section{Discussion}

In the present study, miR-219-5p was discovered to possibly be involved in the development of cyanotic CHD. The present research showed that the expression of miR-219-5p was significantly upregulated in patients with cyanotic CHD and hypoxic cardiomyocytes compared with patients with acyanotic CHD and normal untreated cardiomyocytes, respectively. Downregulation of miR-219-5p increased hypoxia-induced cardiomyocyte viability and inhibited hypoxia-induced cardiomyocyte apoptosis by targeting LRH-1. Therefore, inhibition of miR-219-5p expression may be a potential mechanism for cardioprotection against chronic hypoxia.

Chronic hypoxia is the basic pathophysiological process associated with cyanotic CHD (18). A previous study reported that reduction of cell viability, invasion and migration, and increased cell apoptosis could be induced by hypoxia in $\mathrm{H} 9 \mathrm{C} 2$ cells (19). In addition, hypoxia could enhance cardiomyocyte apoptosis to induce cytotoxicity (20). Hypoxia treatment triggered a variety in miRNA expression abnormalities, such as miR-181 and miR-532-5p, in cardiomyocytes $(21,22)$. In the present study, H9C2 cell viability was inhibited and apoptosis was increased after $72 \mathrm{~h}$ of hypoxia induction. miR-219-5p expression in patients with cyanotic CHD and in hypoxia-induced cardiomyocytes was significantly upregulated compared with patients with acyanotic CHD and normal cardiomyocytes, respectively.

miR-219-5p has been extensively studied in several disease processes. A previous study reported that miR-219-5p inhibitor protected against spinal cord injury by regulating the LRH-1/Wnt/ $\beta$-catenin signaling pathway (23). miR-219-5p promoted the metastasis and growth of hepatocellular carcinoma via downregulating cadherin 1 (24). Additionally, a recent study found that miR-219-5p was markedly increased in hypoxic keratinocytes and targeted transmembrane protein 98 
to inhibit wound healing in keratinocytes under hypoxic conditions (25). However, to the best of our knowledge, few studies have reported the potential role of miR-219-5p in heart diseases. In the present research, the data showed that inhibition of miR-219-5p reduced cell apoptosis and enhanced cell viability in hypoxia-induced cardiomyocytes, indicating that inhibition of miR-219-5p might play a protective role in the progression of cyanotic CHD.

In the present research, LRH-1 was shown to be a direct target of miR-219-5p. LRH-1 is known to be a co-activator of the Wnt/ $\beta$-catenin signaling pathway (26). Dysregulation of $\mathrm{Wnt} / \beta$-catenin signaling is involved in various cellular and biological processes, including cell differentiation, proliferation and apoptosis (27). Dysregulated Wnt/ $\beta$-catenin pathway is implicated in the onset and progression of hypertensive heart disease (28). A previous study reported that hypoxia-inducible factor $2 \alpha$ induced cardiomyogenesis via enhancing the activation of the Wnt/ $\beta$-catenin signaling in mouse embryonic stem cells (29). These studies indicated a positive role of $\mathrm{Wnt} / \beta$-catenin in cardiac protection. In the present study, the results showed that inhibition of the LRH-1/Wnt/ $\beta$-catenin pathway in cardiomyocytes by hypoxia could be reversed by miR-219-5p inhibitor transfection. Moreover, LRH-1 siRNA transfection could reverse the effects of miR-219-5p inhibitor on hypoxia-induced cardiomyocytes. However, a limitation of the current research is the absence of another experimental condition such as a hypoxia group co-transfected with both inhibitor and control siRNA.

In conclusion, the present research demonstrated that the expression of miR-219-5p was increased in patients with cyanotic CHD and hypoxic cardiomyocytes. Downregulation of miR-219-5p increased cell viability and reduced apoptosis of hypoxia-induced cardiomyocytes via affecting the LRH-1/Wnt/ $\beta$-catenin signaling pathway. These results suggested that miR-219-5p may be a potential target in the clinical therapeutic treatment of cyanotic CHD. However, the study is only a preliminary analysis of the role of miR-219-5p in congenital heart disease. To further confirm the role of miR-219-5p in CHD, more in-depth experimental research is still required. For example, the role of miR-219-5p/LRH-1 in other types of cardiomyocytes (such as human primary cardiomyocytes and mouse cardiomyocytes) could be investigated. The role of miR-219-5p/LRH-1 in CHD could be investigated in vivo. The relationship between the expression of miR-219-5p/LRH-1 in patients with CHD and the clinical pathological features of patients with CHD could also be studied.

\section{Acknowledgements}

Not applicable.

\section{Funding}

No funding was received.

\section{Availability of data and materials}

All datasets used and/or generated during the current study are available from the corresponding author on reasonable request.

\section{Authors' contributions}

$\mathrm{CH}$ contributed to the conception and design of the study. $\mathrm{SH}$ and FW contributed to the data acquisition, analysis and interpretation. HD analyzed the data and prepared the manuscript. All authors read and approved the final manuscript.

\section{Ethics approval and consent to participate}

The study protocol was approved by the Ethics Committee of Huai'an First People's Hospital (Huai'an, China). Written informed consents were obtained from the legal guardians of all participants.

\section{Patient consent for publication}

All patients' guardians provided consent for publication.

\section{Competing interests}

The authors declare that they have no competing interests.

\section{References}

1. Cassidy AR, White MT, DeMaso DR, Newburger JW and Bellinger DC: Executive function in children and adolescents with critical cyanotic congenital heart disease. J Int Neuropsychol Soc 21: 34-49, 2015.

2. Hoffman JI and Kaplan S: The incidence of congenital heart disease. J Am Coll Cardiol 39: 1890-1900, 2002.

3. Haseba S, Sakakima H, Nakao S, Ohira M, Yanagi S, Imoto Y, Yoshida A and Shimodozono M: Early postoperative physical therapy for improving short-term gross motor outcome in infants with cyanotic and acyanotic congenital heart disease. Disabil Rehabil 40: 1694-1701, 2018.

4. Cordina RL and Celermajer DS: Chronic cyanosis and vascular function: Implications for patients with cyanotic congenital heart disease. Cardiol Young 20: 242-253, 2010.

5. Bartel DP: MicroRNAs: Genomics, biogenesis, mechanism, and function. Cell 116: 281-297, 2004.

6. Wang L, Tian D, Hu J, Xing H, Sun M, Wang J, Jian Q and Yang H: miRNA-145 regulates the development of congenital heart disease through targeting FXN. Pediatr Cardiol 37: 629-636, 2016.

7. Zhang Y, Peng B and Han Y: miR-182 alleviates the development of cyanotic congenital heart disease by suppressing HES1. Eur J Pharmacol 836: 18-24, 2018.

8. Cheng J, Deng R, Zhang P, Wu C, Wu K, Shi L, Liu X, Bai J, Deng M, Shuai X, et al: miR-219-5p plays a tumor suppressive role in colon cancer by targeting oncogene Sall4. Oncol Rep 34: 1923-1932, 2015.

9. Jiang Y, Yin L, Jing $\mathrm{H}$ and Zhang H: MicroRNA-219-5p exerts tumor suppressor function by targeting ROBO1 in glioblastoma. Tumour Biol 36: 8943-8951, 2015.

10. Fayard E, Auwerx J and Schoonjans K: LRH-1: An orphan nuclear receptor involved in development, metabolism and steroidogenesis. Trends Cell Biol 14: 250-260, 2004.

11. Wang ZN, Bassett M and Rainey WE: Liver receptor homologue-1 is expressed in the adrenal and can regulate transcription of 11 beta-hydroxylase. J Mol Endocrinol 27: 255-258, 2001.

12. Grgurevic N, Tobet S and Majdic G: Widespread expression of liver receptor homolog 1 in mouse brain. Neuro Endocrinol Lett 26: 541-547, 2005.

13. Wu C, Feng J, Li L, Wu Y, Xie H, Yin Y, Ye J and Li Z: Liver receptor homologue 1 , a novel prognostic marker in colon cancer patients. Oncol Lett 16: 2833-2838, 2018.

14. Bianco S, Jangal M, Garneau D and Gévry N: LRH-1 controls proliferation in breast tumor cells by regulating CDKN1A gene expression. Oncogene 34: 4509-4518, 2015.

15. Xiao L, Wang Y, Xu K, Hu H, Xu Z, Wu D, Wang Z, You W, $\mathrm{Ng} \mathrm{CF}, \mathrm{Yu} \mathrm{S}$, et al: Nuclear receptor LRH-1 functions to promote castration-resistant growth of prostate cancer via its promotion of intratumoral androgen biosynthesis. Cancer Res 78: 2205-2218, 2018. 
16. 16. Jian Z, Li JB, Ma RY, Chen L, Zhong QJ, Wang XF, Wang $\mathrm{W}$, Hong $\mathrm{Y}$ and Xiao $\mathrm{YB}$ : Increase of macrophage migration inhibitory factor (MIF) expression in cardiomyocytes during chronic hypoxia. Clin Chim Acta 405: 132-138, 2009.

17. Livak KJ and Schmittgen TD: Analysis of relative gene expression data using real-time quantitative PCR and the 2(-Delta Delta C(T)) Method. Methods 25: 402-408, 2001.

18. Piccoli M, Conforti E, Varrica A, Ghiroldi A, Cirillo F, Resmini G, Pluchinotta F, Tettamanti G, Giamberti A, Frigiola A, et al: NEU3 sialidase role in activating HIF-1 $\alpha$ in response to chronic hypoxia in cyanotic congenital heart patients. Int J Cardiol 230: 6-13, 2017.

19. Gong L, Xu H, Chang H, Tong Y, Zhang T and Guo G: Knockdown of long non-coding RNA MEG3 protects H9c2 cells from hypoxia-induced injury by targeting microRNA-183. J Cell Biochem 119: 1429-1440, 2018.

20. Park M, Youn B, Zheng XL, Wu D, Xu A and Sweeney G: Globular adiponectin, acting via AdipoR1/APPL1, protects H9c2 cells from hypoxia/reoxygenation-induced apoptosis. PLoS One 6: e19143, 2011.

21. Hao P, Cao X, Zhu Z, Gao C, Chen Y and Qi D: Effects of miR-181a targeting XIAP gene on apoptosis of cardiomyocytes induced by hypoxia/reoxygenation and its mechanism. J Cell Biochem: Nov 28, 2018 (Epub ahead of print).

22. Ma J, Zhang J, Wang Y, Long K, Wang X, Jin L, Tang Q, Zhu L, Tang G, Li X, et al: miR-532-5p alleviates hypoxia-induced cardiomyocyte apoptosis by targeting PDCD4. Gene 675: 36-43, 2018.

23. Li J, Li L and Shen Y: Protective role of microRNA-219-5p inhibitor against spinal cord injury via liver receptor homolog-1/Wnt/ $\beta$-catenin signaling pathway regulation. Exp Ther Med 15: 3563-3569, 2018.
24. Yang J, Sheng YY, Wei JW, Gao XM, Zhu Y, Jia HL, Dong QZ and Qin LX: MicroRNA-219-5p promotes tumor growth and metastasis of hepatocellular carcinoma by regulating cadherin 1 . BioMed Res Int 2018: 4793971, 2018.

25. Tang Q and Ran H: MicroRNA-219-5p inhibits wound healing by targeting TMEM98 in keratinocytes under normoxia and hypoxia condition. Eur Rev Med Pharmacol Sci 22: 6205-6211, 2018.

26. Botrugno OA, Fayard E, Annicotte JS, Haby C, Brennan T, Wendling O, Tanaka T, Kodama T, Thomas W, Auwerx J, et al: Synergy between LRH-1 and beta-catenin induces G1 cyclin-mediated cell proliferation. Mol Cell 15: 499-509, 2004.

27. Fodde R and Brabletz T: Wnt/beta-catenin signaling in cancer stemness and malignant behavior. Curr Opin Cell Biol 19: 150-158, 2007.

28. Zhao Y, Wang C, Wang C, Hong X, Miao J, Liao Y, Zhou L and Liu Y: An essential role for Wnt/ $\beta$-catenin signaling in mediating hypertensive heart disease. Sci Rep 8: 8996, 2018.

29. Sun X, Pang L, Shi M, Huang J and Wang Y: HIF2 $\alpha$ induces cardiomyogenesis via Wnt/ $\beta$-catenin signaling in mouse embryonic stem cells. J Transl Med 13: 88, 2015.

This work is licensed under a Creative Commons Attribution-NonCommercial-NoDerivatives 4.0 International (CC BY-NC-ND 4.0) License. 